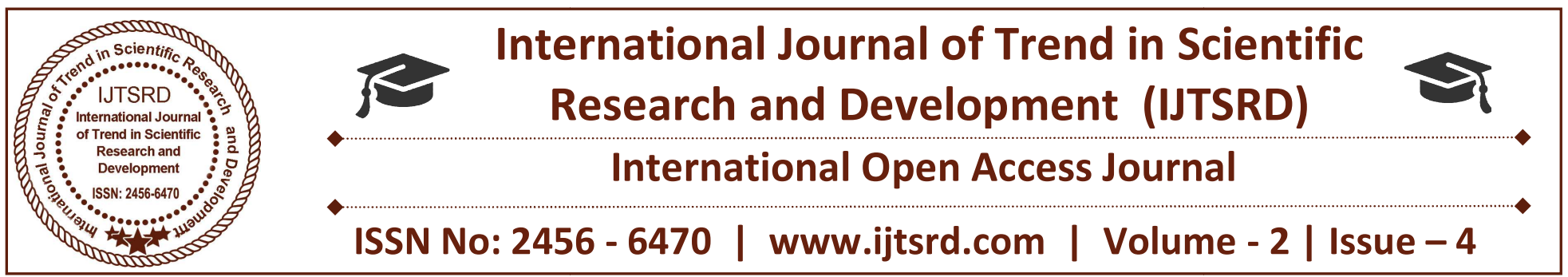

\title{
Concrete Mixture Assembly Line Improvement using ARENA Simulation - A Case Study
}

\author{
Tushar D. Kumbhani, Mukesh C. Chaudhari \\ Assistant Professor, Mechanical Engineering Department, Vadodara Institute of Engineering, \\ Vadodara, Gujarat, India
}

\begin{abstract}
Since last decade, simulation is most required part of industries of all level. In simulation process plant layout to utilization of resources can be covered. In current case study Arena simulation model is made for line balancing and man power utilization. Case study is carried out at Esquire Machines Pvt. Ltd. Vadodara. Final product/assembly is completely made out from 6 assemblies/subassemblies. The simulation model is prepared in ARENA Simulation software (student version). As an input for model real time is collected/counted with the help of mobile stopwatch for each and every process. Data is distributed for its validation to use in simulation model on EasyFit Distribution software. Different scenarios are tested to optimize and balance the line and best solution is discussed.
\end{abstract}

Keywords: ARENA; Discrete event simulation; Bottleneck; Production line; Line balancing

\section{INTRODUCTION}

Automation and simulation must be strong for any organization if their products are customized. Automation for medium scale organization is difficult because of high initial cost. Automation is also not right choice for MSO, producing customize product. Mostly MSO runs on manual efforts of manpower, so chances of errors and accidents are always there. Any MSO survives only on time of response, cost of production, MRP, manufacturing flexibility. These key elements of profit encourage developers and software designers to work on specific side to increase profit and eliminate unnecessary events or process by suggesting short and profitable path. For simulation of product design and product there are many software in market and widely used in all type of organizations. Simulation of production line or line balance (assembly line balance) is not quite famous in India.

Arena, one of software which is used by organizations to develop production line, to balance assembly line, to detect bottleneck(s) in assembly line, to develop or modify plant layout and also help to manage productive hours of men power[1].

Arena discrete event simulation software is available in two categories, first is full version (license version for professional use) and second is student version (research use for students only). Student version doesn't provide all modules of software.

For use and validation of measured data (measured time for different processes) to run simulation model EasyFit data distribution software is used. Measured time is distributed with different distribution format and nature of data is observed. There is not large variation in data when different distributions applied hence measured data is taken to run simulation model [6].

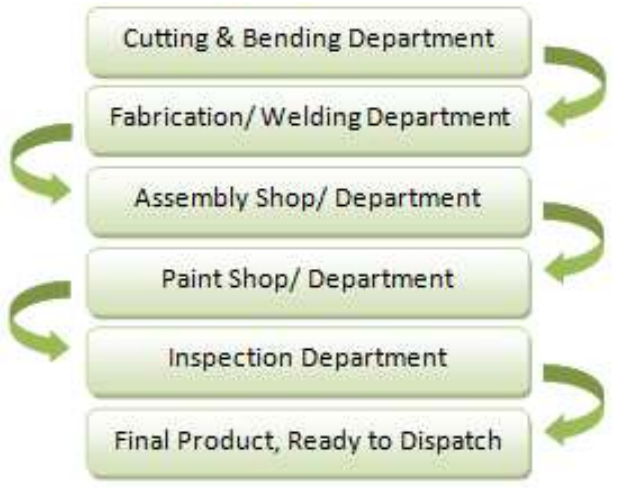

Fig-1: Flow of work 
Concrete mixtures are available in wide range for cement related work. Hand-feed concrete mixture is most widely used machine and old machine also. Manufacturing of Hand-feed machine (capacity of 3001tr, 4001tr) is completed in line production having different departments or shops. Figure-1 shows the flow of work and respective department. Esquire machines is well known in overseas market for it's customize production ability.

In line production at Esquire machines product mixup, priority change, and rush of work at any stage of production line or bottleneck, etc issues often happens. From this entire bottleneck is highest problem creator and bottleneck directly effects on efficiency of plant or company. In this study we have identified and tried to reduce or eliminate bottleneck from line production of Hand feed concrete machine.

\section{Objectives of Study:}

Objectives of the study are as below

- To reduce rush of work

- To eliminate product mix ups

- To reduce or eliminate bottleneck

- To utilize man working hours

\section{RESEARCH METHODOLOGY}

To study any product always first basic information is required regarding that product like material used to build it, design, manufacturing process, quality aspects, functions, life of product, challenges during production(manufacturing), methods of dispatch, etc. To solve the case of bottleneck in our study following (figure-2) methodology is taken in which problem identification, model of actual system, improvement in model, comparison of actual and improved model are key stages. At the end of study few suggestions are provided and which are appreciated by authority and management team also [2].

\section{BOTTLENECK IDENTIFICATION}

For identification of bottleneck area in production first knowledge of complete flow of production line is required. In this case study, our interested area is only production's main assembly line for that one model is prepared in ARENA Simulation software which is model of actual system followed by assembly shop to assemble different parts or sub assemblies.

Three workers are must required to run assembly line in actual system. If simulation runs for a day shift (eight hours), run setup will be like as shown in figure-3. Workers practice is in batch production system so they are taking FIVE machines assembly parts to do work at start of shift/replication (cycle). At the end of shift assembly line work status will like below figure in which under last module named "fg" there is number 3 which shows that 3 machines are completed out of 5(number of input during a shift)[3].

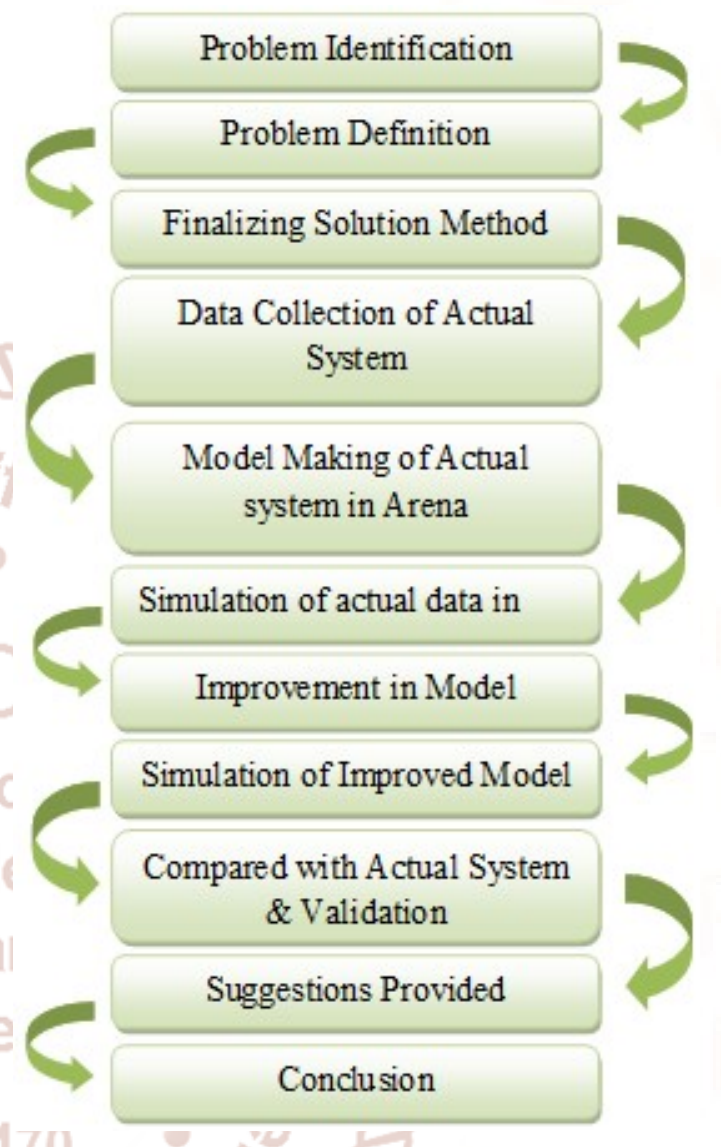

Fig-2: Flow of Work

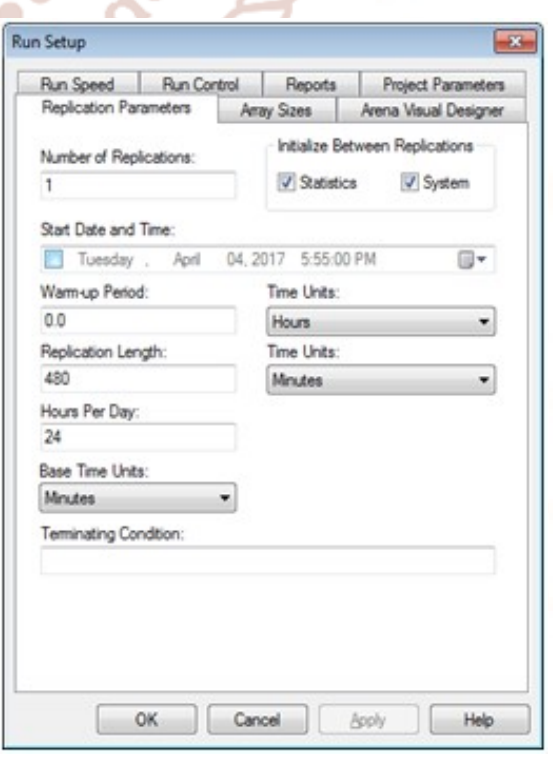

Fig-3: Run setup for Simulation Process 


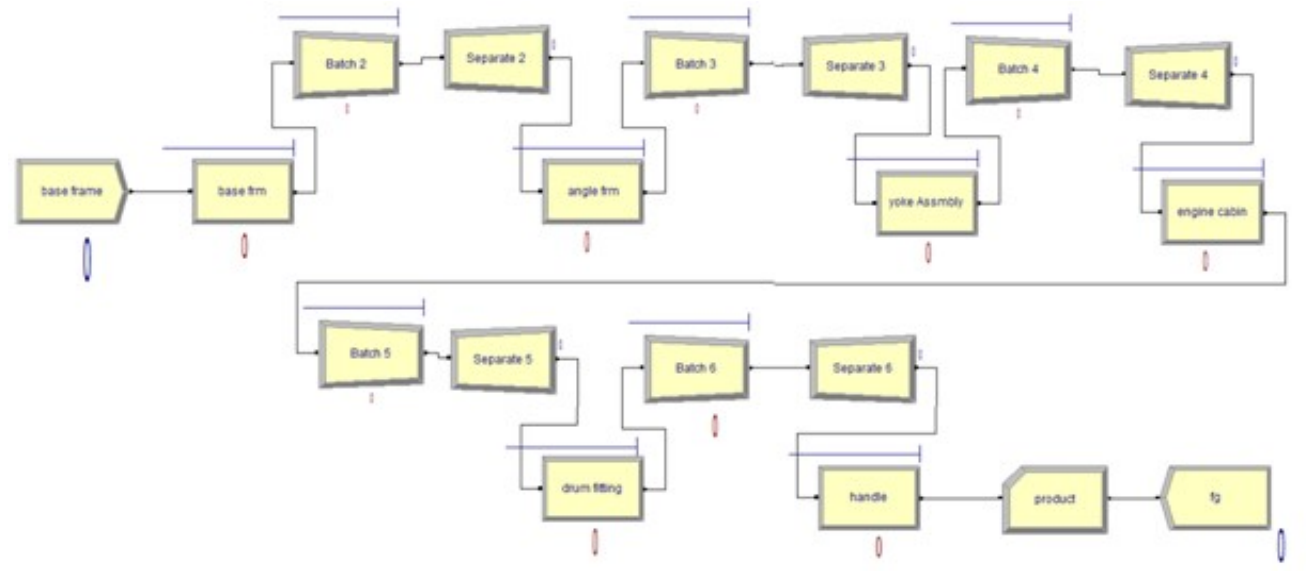

Fig-4: ARENA Simulation Model for Assembly line HF -300 ltr

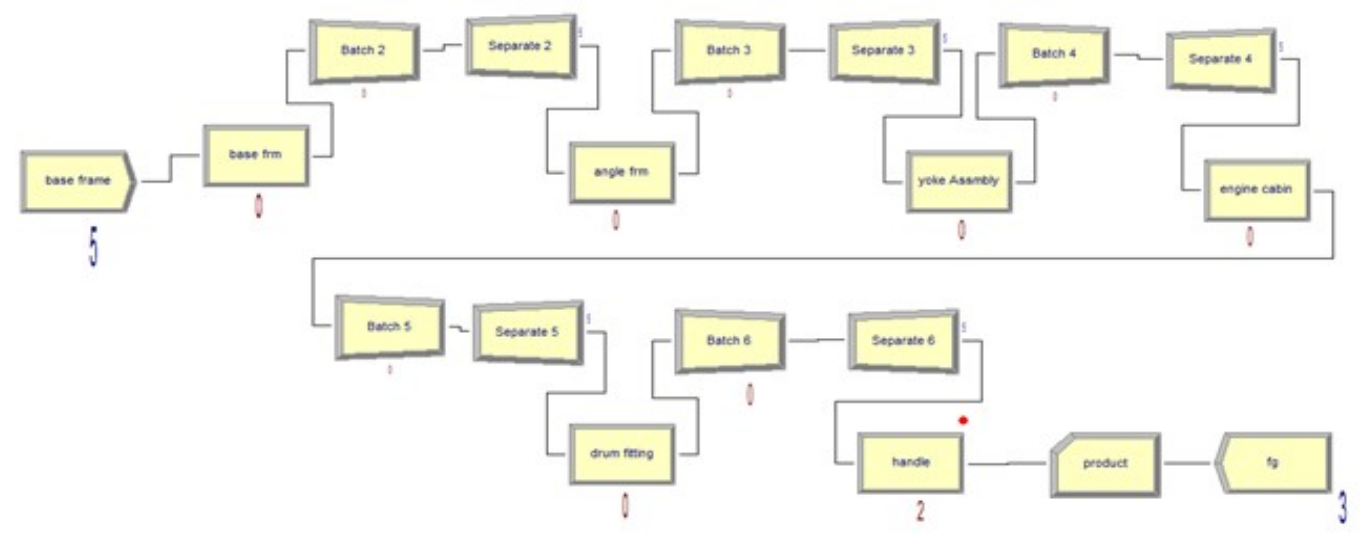

Fig-5: ARENA Simulation modified model for assembly line HF -300 ltr at day (shift) end

Red ball indicates the entities which are in process. At end of day 3 machines are assembled by workers and from remaining 2 , one is in process at drum fitting stage while other one is waiting for in process assembly at handle fitting stage which is last stage of assembly line.

As an improvement in assembly line few more workstations are introduced fro those which are taking more time for the process in actual assembly line like a yoke fitting, an engine cabin fitting and a drum fitting. After introducing few new work stations modified assembly line will be like below [4][8].
From modified assembly line model analysis (figure6) it is clear that at the end of day 10 machines are assembled and 4 machines are waiting for fifth machine which is in process at angle fitting stage. After that they will be separated in two different assembly lines for next assembly stages.

From table-1 we can say that cycle time for actual and modified model is different because in modified model we have introduced new assembly line for yoke fitting, engine cabin fitting and drum fitting assembly process. Value added time and waiting time for entities are much higher in actual model then modified model.

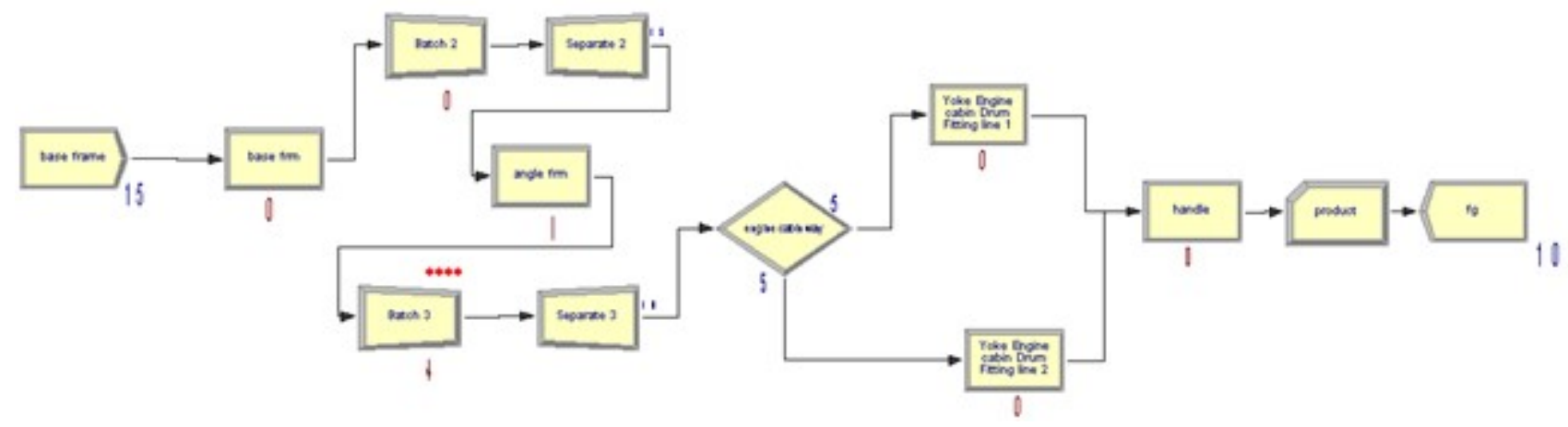

Fig-6: ARENA Simulation modified model for assembly line HF -300 ltr at day (shift) end 
International Journal of Trend in Scientific Research and Development (IJTSRD) ISSN: 2456-6470

Table-1: Comparison of actual model and modified model having 3 inputs at constant time

\begin{tabular}{|c|c|c|}
\hline & $\begin{array}{l}\text { Actual } \\
\text { model }\end{array}$ & $\begin{array}{c}\text { Modified } \\
\text { model }\end{array}$ \\
\hline Cycle time & $29340 \mathrm{sec}$ & $11736 \mathrm{sec}$ \\
\hline Number In & 5 & 15 \\
\hline Number Out & 3 & 10 \\
\hline $\begin{array}{c}\text { Value added } \\
\text { time }\end{array}$ & 97.8045 & 71.635 \\
\hline Waiting time & 371.3 & 121.37 \\
\hline $\begin{array}{c}\text { TOTAL } \\
\text { TIME }\end{array}$ & 469.12 & 193 \\
\hline $\begin{array}{l}\text { Work in } \\
\text { process }\end{array}$ & 2 & 5 \\
\hline $\begin{array}{c}\text { Base frame } \\
\text { queue }\end{array}$ & 5.1928 & 5.2004 \\
\hline $\begin{array}{c}\text { Angle frame } \\
\text { queue }\end{array}$ & 36.5008 & 36.5007 \\
\hline Yoke queue & 30.167 & - \\
\hline $\begin{array}{c}\text { Engine cabin } \\
\text { queue }\end{array}$ & 58.1307 & - \\
\hline $\begin{array}{c}\text { Drum fitting } \\
\text { queue }\end{array}$ & 52.3432 & - \\
\hline Handle queue & 9.9504 & 2.6501 \\
\hline $\begin{array}{c}\text { Assembly line } \\
1\end{array}$ & - & 35.3238 \\
\hline $\begin{array}{c}\text { Assembly line } \\
2\end{array}$ & - & 35.3192 \\
\hline $\begin{array}{c}\text { TOTAL } \\
\text { TIME }\end{array}$ & 192.2839 & 114.9942 \\
\hline
\end{tabular}

For all processes queue time is also compared but here queue time is higher in modified model but if we compare that time with our output in modified model, we have less queue time then actual model. So modified model is efficient then actual assembly line $[5,9]$.

\section{SUGGESTIONS PROVIDED}

Few suggestions were provided to company to improve line efficiency and better manpower utilization. Suggestions were like these:

$>$ Introduce one more assembly workstation having only three processes: a yoke fitting, an engine cabin fitting and a drum fitting.

$>$ Three more manpower can be used for continuous work output.

$>$ Simulation is also possible for cutting, bending and fabrication shop of our discussed product HF-300 ltr.
$>$ There are huge scope of improvement in work handling and processes.

$>$ Manpower working with assembly line should have enough experience of particular machine assembly.

$>$ Fixture development for cutting operation of raw material is also possible.

ARENA simulation can also be done on other product's data and production line of company for better understanding of bottlenecks.

$>$ ARENA can be used for layout problems also.

\section{CONCLUSION}

Simulation result provided by ARENA is useful to compare actual system with modified system. In actual system only three machines can assembled with the help of three man power but in modified system ten machines are assembled by six man power for same time period. Without any training and with same instrument these results are concluded. Thus ARENA is useful to increase plant efficiency without affecting actual system.

\section{REFERENCES}

1) Jadrić, M., Ćukušić, M., \& Bralić, A. (2015). Comparison of discrete event simulation tools in an academic environment. Croatian Operational Research Review, 5(2), 203-219.

2) Bin Mohd Said, M. A., \& Ismail, N. B. (2013). Virtual Production Line Layout Modeling Using Arena Simulation Software. In Applied Mechanics and Materials (Vol. 393, pp. 42-48). Trans Tech Publications.

3) Parihar, S., \& Bhar, C. (2016). Development of framework for mitigating production bottleneck related risks: a case study on thermosetting plastic products manufacturing firm. Management Insight, 11(2).

4) Kamar, A. N. N., Bakar, N. H. A., Dahan, S. M., Adham, A. A. J., \& Sorooshian, S. (2016). Improving Productivity by Simulate Facility Layout: A Case Study in a Car Component Manufacturer. In International Journal of Industrial Management, Malaysia, June 2016.

5) Ziaei, M., Sajadi, S. M., \& Tavakoli, M. M. (2016). The performance improvement of water pump manufacturing system via multi-criteria decision-making and simulation (a case study: Iran Godakht Company). International Journal of 
International Journal of Trend in Scientific Research and Development (IJTSRD) ISSN: 2456-6470

Productivity and Quality Management, 17(1), 115.

6) Mehrannia, H., \& Pakgohar, A. (2014). USING EASY FIT SOFTWARE FOR GOODNESS-OFFIT TEST AND DATA GENERATION. International Journal of Mathematical Archive (IJMA) ISSN 22295046, 5(1).
7) Parker, S. P. (1984). McGraw-Hill dictionary of scientific and technical terms.

8) Yuniarto, H. (2012). The Shortcomings of Existing Root Cause Analysis Tools. Proc. World Congr. Eng, 3.

9) Ekren, B. Y., \& Ornek, A. M. (2008). A simulation based experimental design to analyze factors affecting production flow time. Simulation Modelling Practice and Theory, 16(3), 278-293.

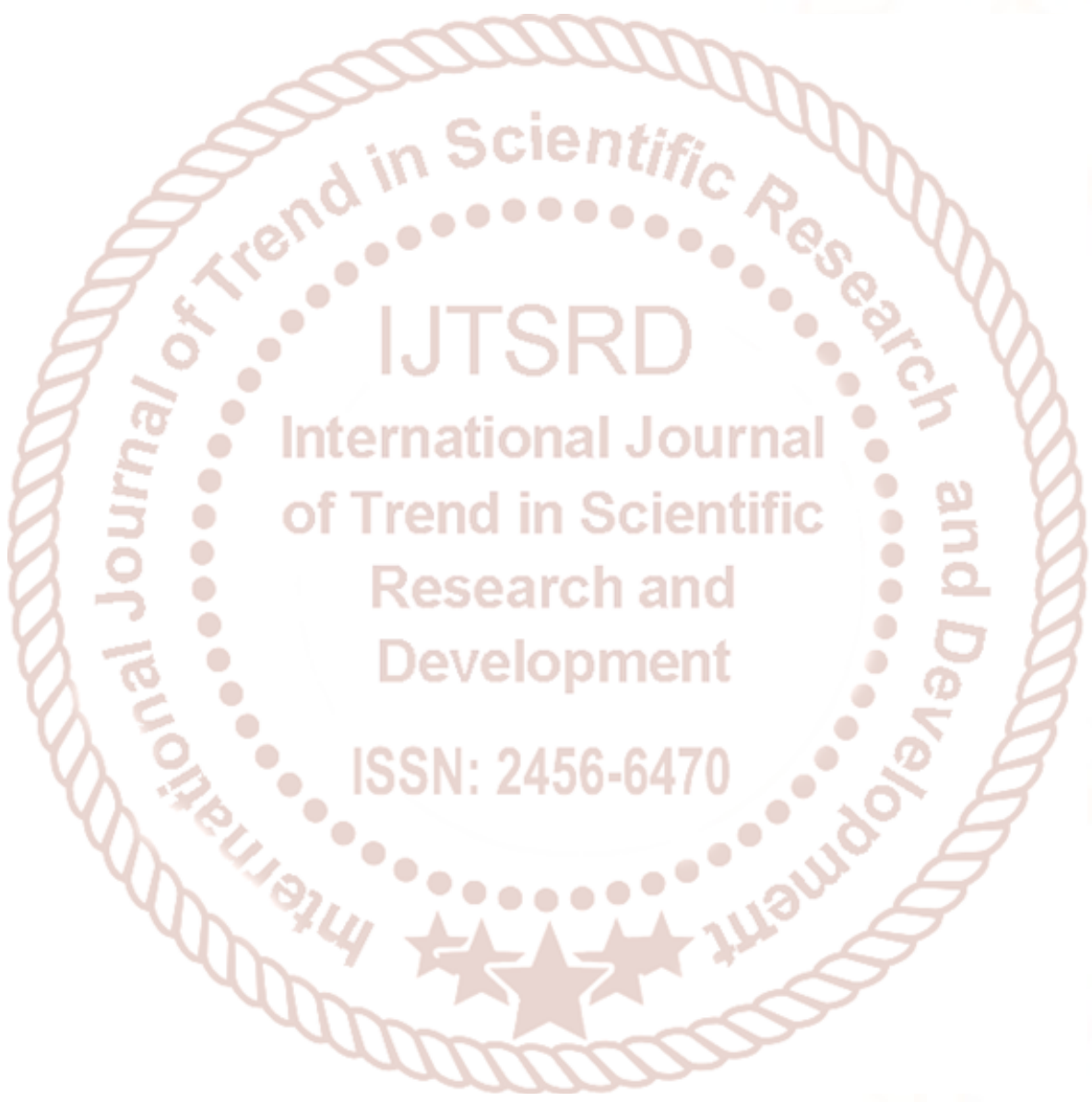

